\title{
Experimental Research on Wall Pressure Distribution in C-D Nozzle at Mach number 1.1 for Area Ratio 3.24
}

\author{
S A Khan, Imran Mokashi, Abdul Aabid, Mohammed Faheem
}

\begin{abstract}
In this experimental investigation the work reported is about the influence of control on the flow field in the suddenly expanded duct at low supersonic Mach number. A Convergent-divergent $(C D)$ nozzle was designed and fabricated out of brass material assembled with the suddenly expanded duct which was also made of brass material. At the re-circulation zone, the flow field was controlled by using the micro jets of 1 mm diameter as an orifice and the control was arranged at an interval of 90 degrees at $6.5 \mathrm{~mm}$ from the central axis of the main jet. The measured wall pressure distribution was presented for Mach number 1.1 for the duct diameter of $18 \mathrm{~mm}$ leading to the area ratio 3.24. The $L / D$ ratio of the duct was varied from 1 to 10 , and the nozzle pressure ratio (NPR) considered for the experiments was from 3, 5, 7, 9 and 11. The present results have demonstrated that the micro jets do not influence the flow field in the duct adversely and the flow field remained identical in the presence of control or absence of control.
\end{abstract}

Keywords: Wall Pressure, L/D ratio, NPR, Mach number

\section{INTRODUCTION}

The sudden expansion is a complex flow field which occurs in many engineering problems like in the automobile industry, at the blunt base of the shells, projectiles, rockets, the fuselage of the aircraft, and Bombs. The pressure at the blunt base is lower than the ambient pressure. Due to this low pressure, the component of the base drag is a significant portion of the total drag. The base drag can be as high as 67 $\%$ of the total drag of the aerospace vehicle. In view of the above, there is a need to control the base pressure and hence the drag. When we employ the control either active or passive, it is mandatory to investigate the influence of the control on the flow development in the enlarged duct. This investigation aims to monitor the development of the flow in the enlarged duct.

The study on base pressure control using experimental and numerical work has been highlighted by Khan et al. [1] used the tiny jets as a regulation mechanism to control the base pressure in a suddenly expanded axisymmetric duct. They considered the different Mach number such as 2.0, 2.5 and 3.0 to investigate the effectiveness of the micro jet at these high supersonic Mach numbers to control the base pressure in the separated wake region. Moreover, they also considered the effect of area ratio and length to diameter ratio in the range from 10 to 1 . From their results, they concluded that the micro jet is able to control could help as

Revised Manuscript Received on July 10, 2019

S. Karunya Mechanical Engineering Dept. Faculty of Engineering, IIUM Kuala Lumpur, Malaysia.(sakhan@iium.edu.my)

Imran Mokashi Mechanical Engineering Dept. Faculty of Engineering, IIUM Kuala Lumpur, Malaysia.

Abdul Aabid Mechanical Engineering Dept. Faculty of Engineering, IIUM Kuala Lumpur, Malaysia.

Mohammed Faheem Mechanical Engineering Dept. Faculty of Engineering, IIUM Kuala Lumpur, Malaysia. active controllers for base pressure. With the study of micro jet control effect, Khan et al., [2] investigated the wall pressure distribution from the axi-symmetric duct. They proved that the use of micro jet control would not influence to wall pressure distribution. To attempt wall pressure distribution, they considered the different parameters such as L/D, NPR, and the Mach number. To move on the convergent-divergent nozzle with suddenly expanded axisymmetric duct, later, Khan et al., [3] attempts the number of level of study based on the Mach number such as 1.25, 1.30, $1.48,1.6,1.8$, and 2.0. This gives the more accurate to find the micro jet control effect to control the base pressure actively. To prove the internal supersonic flow on CD nozzle Rehman et al., [4] experimentally investigated the micro jet control of base pressure in the axis-symmetry passage. Kostic et al., [5] validated the experimental results with computational fluid dynamics (CFD) method. In order to achieve the results, the authors used the finite element method with ANSYS commercial tool. The experiments also conducted to investigate the correctly expanded cases with different $\mathrm{L} / \mathrm{D}$ and area ratios [6].

On moving to the next type of this study based on the microjet controller, we also found that some researchers used the design of the experiments method (DOE) to optimize the results. The DOE method is used in industrial manufacturing applications [7]. This technique is used by Quadros et al., [8]-[14] to investigate the base pressure with and without a micro jet controller. The authors used different DOE method to optimize the results. The cases have been used on his studies is based on statistical analysis, surface response methodology, and Taguchi design. The authors also proved the best-fitted level of the factors that can actively control the base pressure using microjet control. Moreover, they also optimized the internal flow of the wall pressure on suddenly expanded CD nozzle.

The next level of study is the CFD method, recently Khan et al., [15] numerically investigated the base pressure control using a micro jet controller. To analyze the results the authors used the finite element post-processing tool (ANSYS FLUENT). The two-dimensional CD nozzle is designed and modelled using ANSYS workbench tool [16]. To assess the effectiveness of micro jet to control the flow field from the nozzle a compressible flow with ideal gas using Sutherland has been considered with $\mathrm{K}-\varepsilon$ standard wall function turbulence model. Furthermore, the CFD method is also used to analyze the different Mach number, $\mathrm{L} / \mathrm{D}$, area ratio and NPR's from the authors [17]-[21].

Published By:

Blue Eyes Intelligence Engineering \& Sciences Publication 
From the above work which has been reviewed in this section, we found that still there a scope of research to investigate furthermore on wall pressure and base pressure flows in a CD nozzle with sudden expansion duct. Therefore, the objective of this paper consists the specific case on Mach number 1.1 for area ratio 3.24 with NPR's 3, 5, 7, 9, 11, CO and $\mathrm{U}$ and L/D from 10 to 1 . The consequences which are obtained based on the present problem is plotted in the results section.

\section{Problem definition}

The thickness of the boundary layer just upstream of the corner determines the base pressure for projectiles and a parameter that was the slenderness ratio that is $L / D$ of projectile divided by the Reynolds number based on length to the one-fifth power for turbulent boundary layers to correlate this result. The suddenly expanded flow field and its nature are shown in Fig. 1.

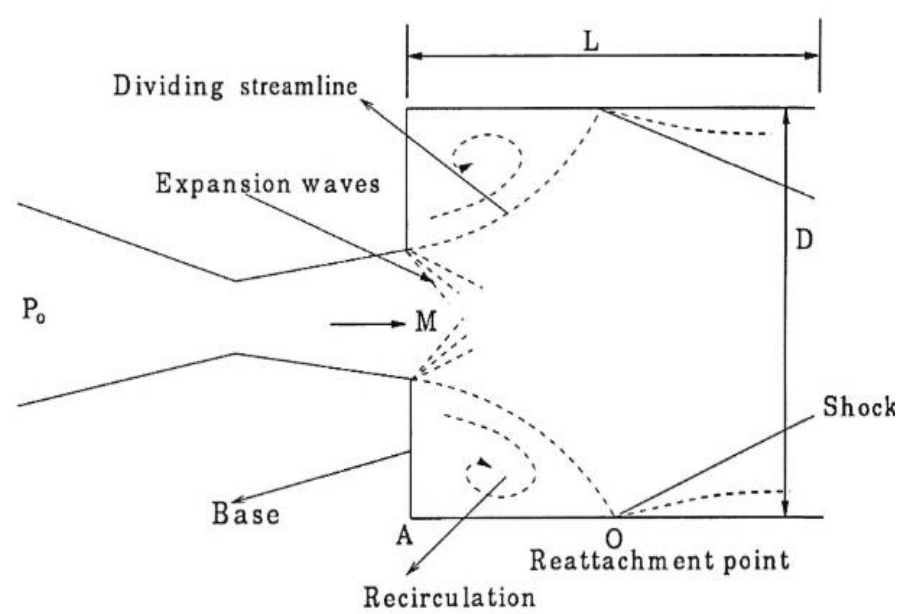

Fig. 1. Sudden Expansion Flow Field.

\section{Experimental Set-up}

Fig. 2 illustrates the procedure used in this investigation as discussed in Ref. [1]

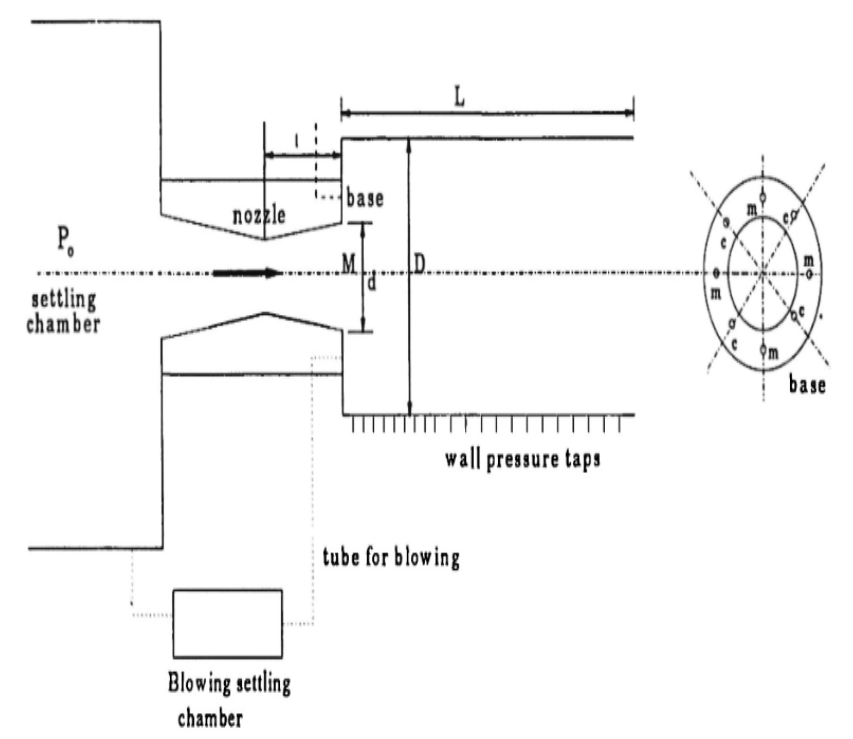

Fig. 2. Experimental Setup.

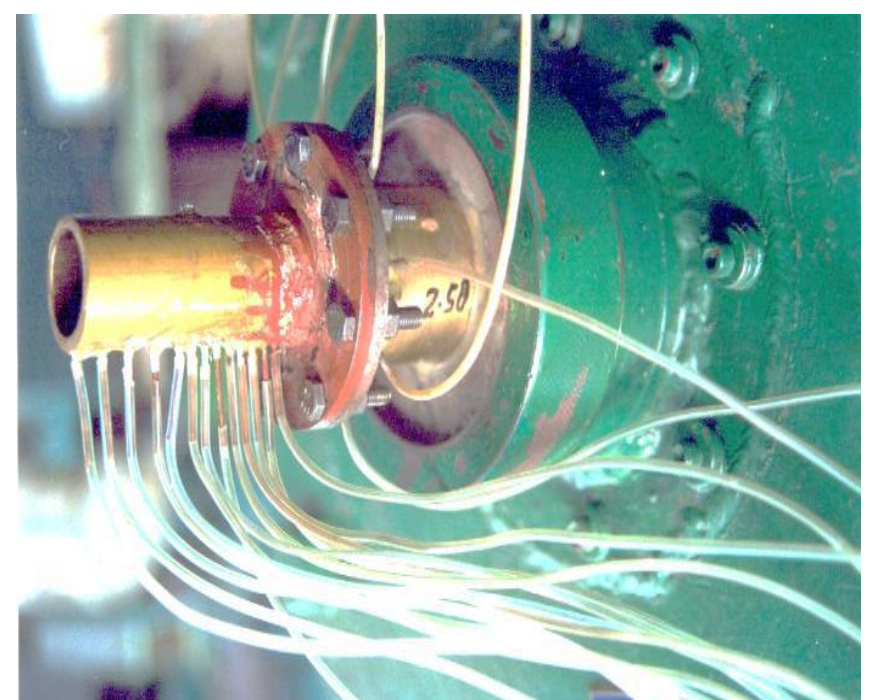

Fig. 3. A View of Suddenly Expanded Duct with Pressure Tapings [22].

\section{Results and Discussion}

Fig. 4 present the wall pressure in the enlarged duct for area ratio 3.24 , for some selected combination of Inertia levels. For this area ratio of 3.24 is the case of slightly increased relief for the expanding flow, compared to the case of area ratio 2.56 . Here, it is interesting to note that the control does not influence in a negative way the flow field.

It is seen from these results that, for $\mathrm{L} / \mathrm{D}=10$ and $\mathrm{M}=$ 1.1 the control does not affect the wall pressure (as in the case of Fig. 4(a) or influences the wall pressure only marginally). Further, it is seen that for NPR's 3 and 5 the fluctuations in the wall pressure level attains steady state within $20 \%$ of the duct diameter. Whereas, for rest of the NPRs the flow field by remained oscillatory, however, the magnitude of the oscillations is less as compared to the previous case due to the effect of increased relief to the free shear layer. Another difference in the present case is the location of the micro jets which was at the center of the base, and for this area ratio, they are close to the main jet.

Fig. 4(b) presents similar wall pressure results for $\mathrm{L} / \mathrm{D}=8$ as was observed in Fig. 4(a) with the reduced oscillations due to the reduced duct length. Fig. $4((\mathrm{c})$ to $(\mathrm{d}))$ represent the wall pressure results for $\mathrm{L} / \mathrm{D}=6$ and 5 with the exception that due to the reduction in the $L / D$ ratio there is some influence of the back pressure and the peak wall pressure values. These values are higher than that those were for higher $\mathrm{L} / \mathrm{D}$ ratios namely for the case of $\mathrm{L} / \mathrm{D}=5$ with the $20 \%$ increased value of the peak wall pressure value. Nevertheless, the flow field has smoothened in the duct as observed earlier, and the wall pressure values with and without control have identical values. This trend continues until $\mathrm{L} / \mathrm{D}=4,3$ and 2 (Fig. 4((e) to (g)), then later for lowest $\mathrm{L} / \mathrm{D}$ like $\mathrm{L} / \mathrm{D}=1$, it is evident that this length is not sufficient for the flow to remain attached with the duct wall hence we should not draw the inference. 


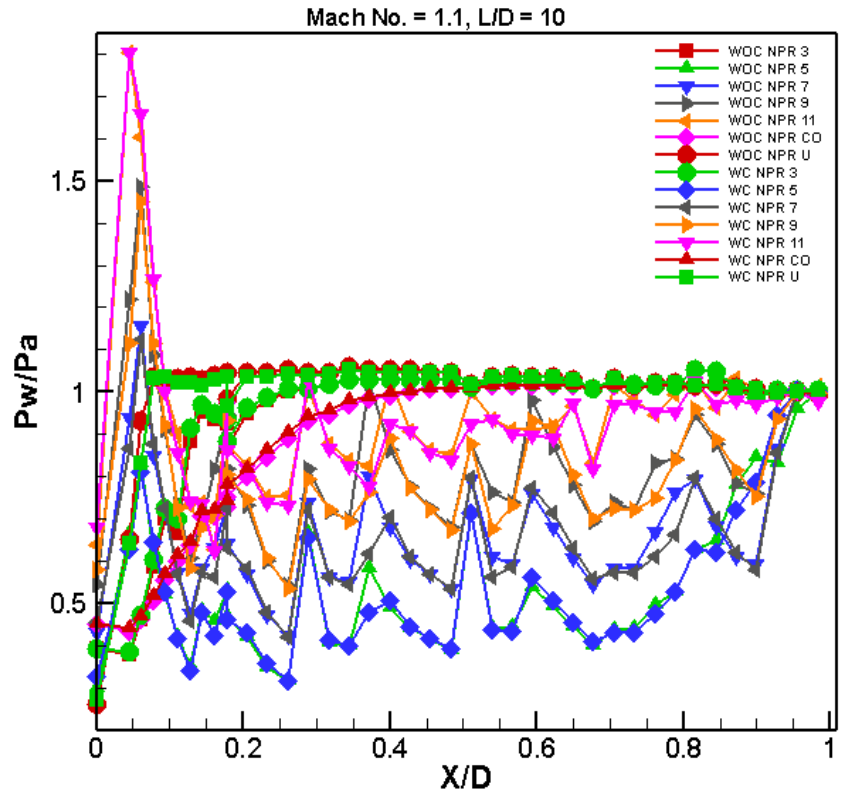

Fig. 4(a). Wall Pressure Vs. X/D

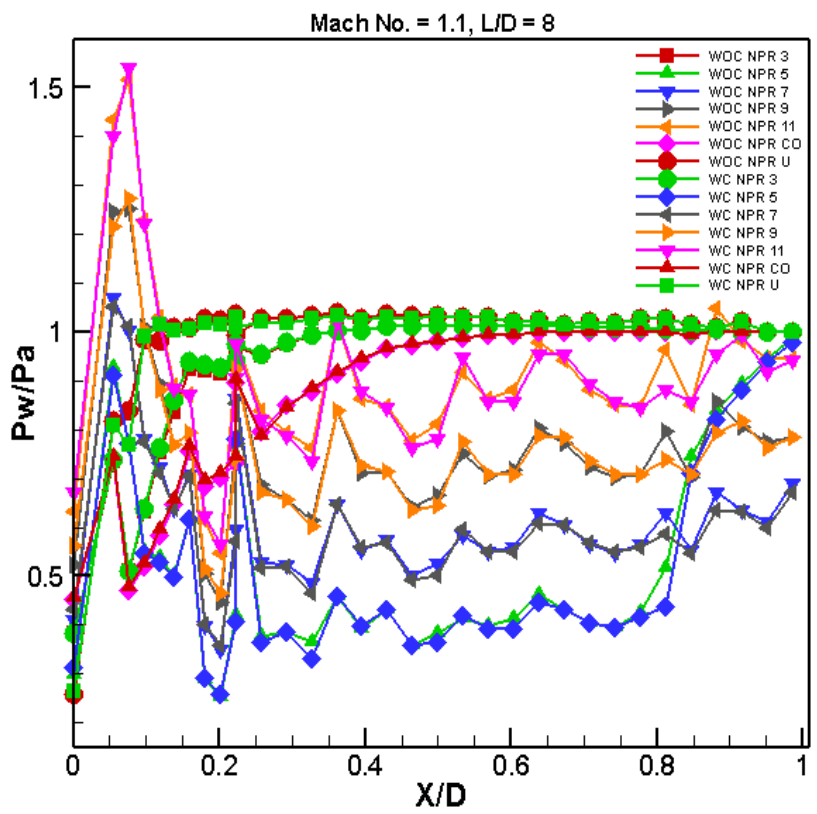

Fig. 4(b). Wall Pressure Vs. X/D

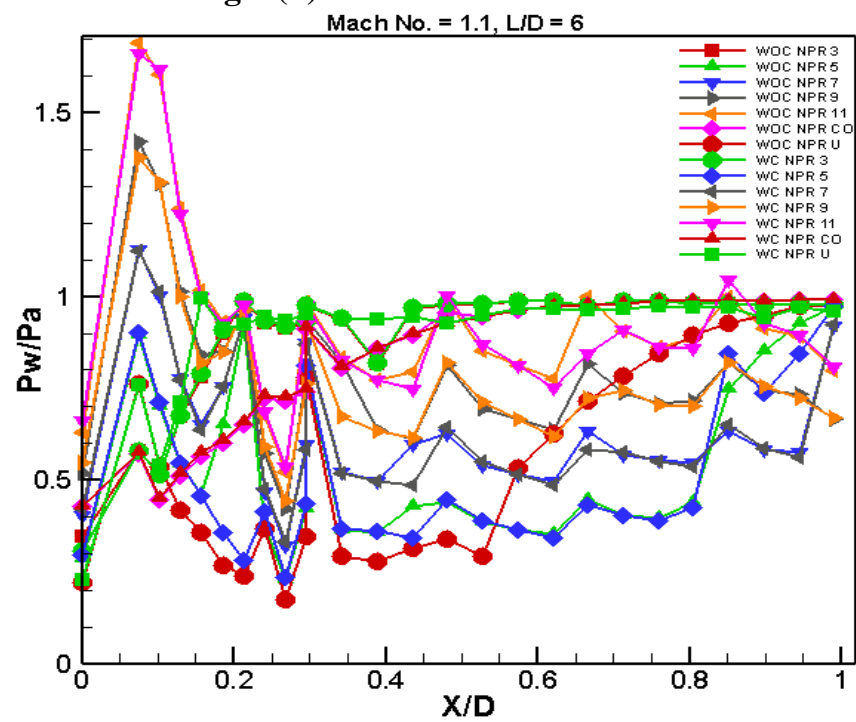

Fig. 4(c). Wall Pressure Vs. X/D

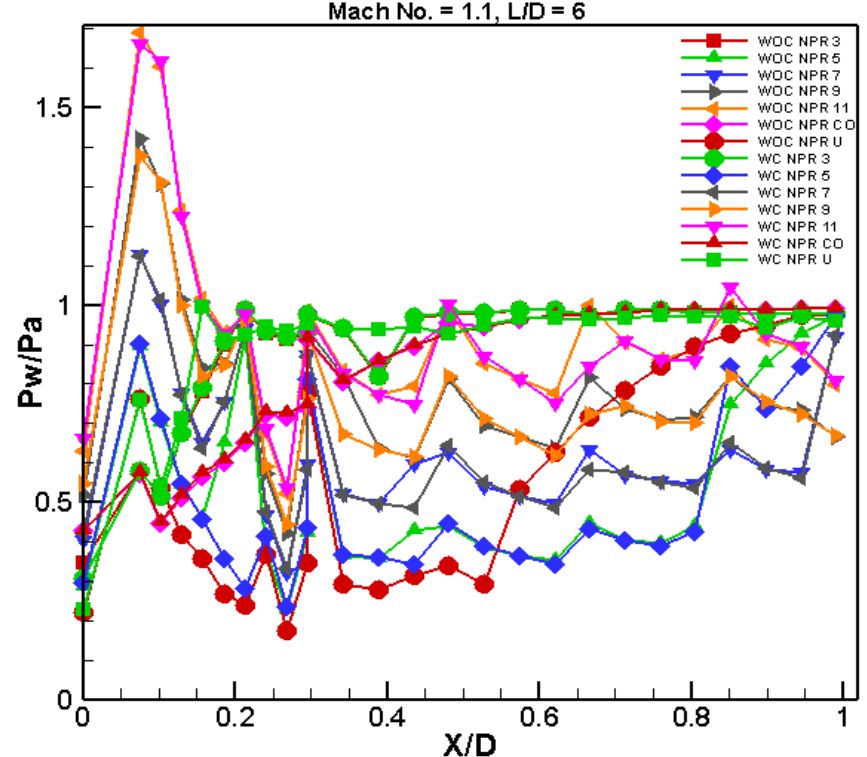

Fig. 4(d). Wall Pressure Vs. X/D

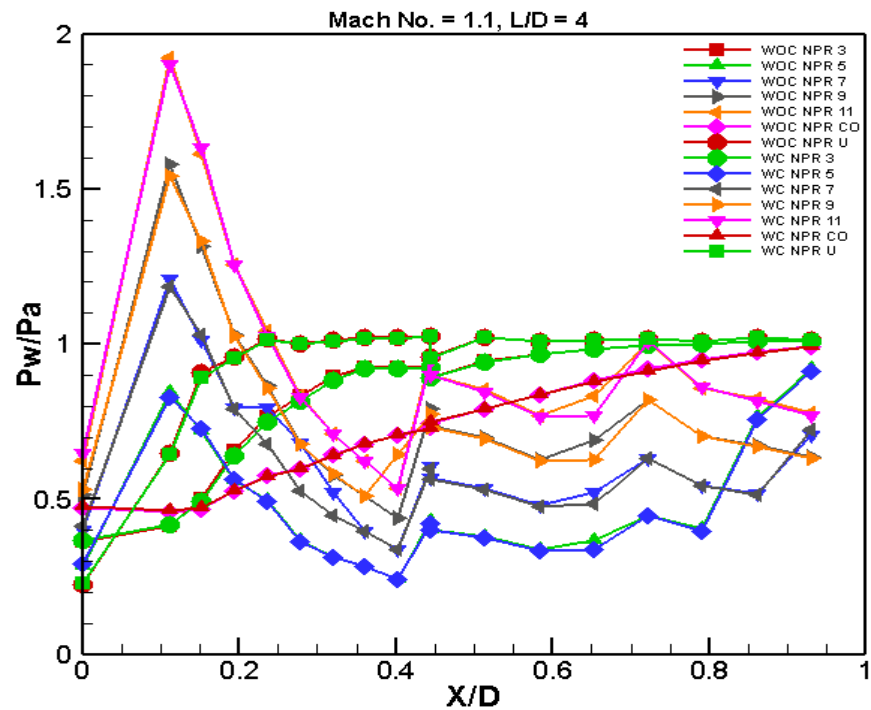

Fig. 4(e). Wall Pressure Vs. X/D

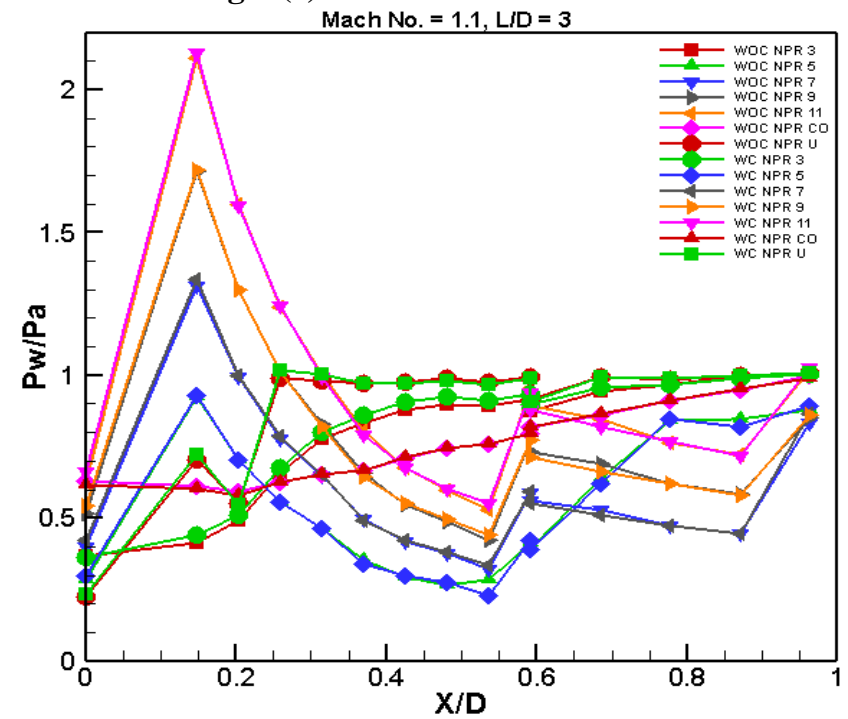

Fig. 4(f). Wall Pressure Vs. X/D

Published By:

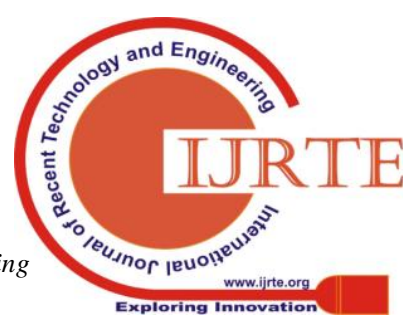




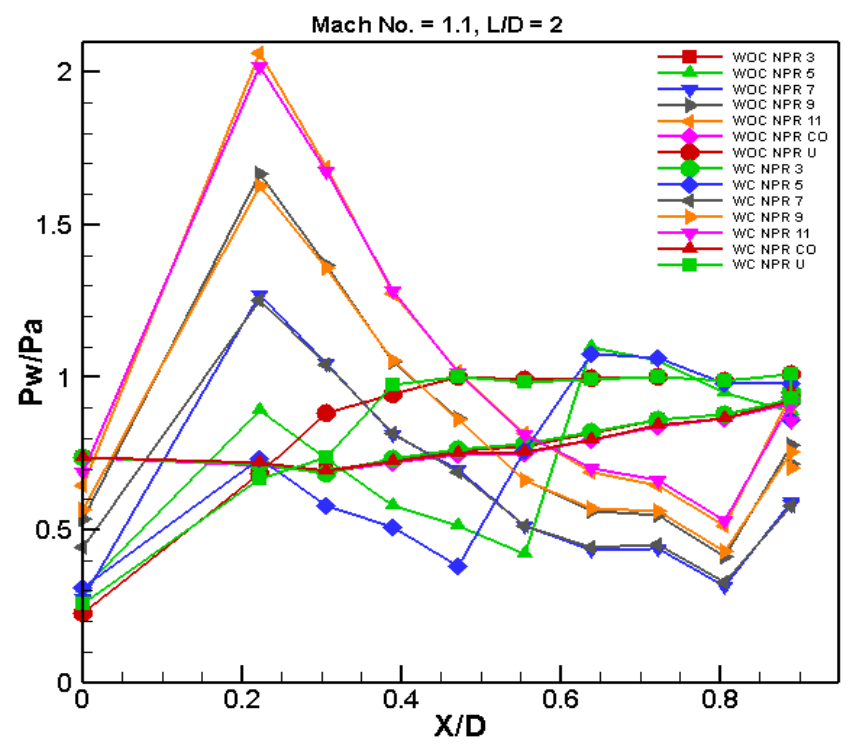

Fig. 4(g). Wall Pressure Vs. X/D

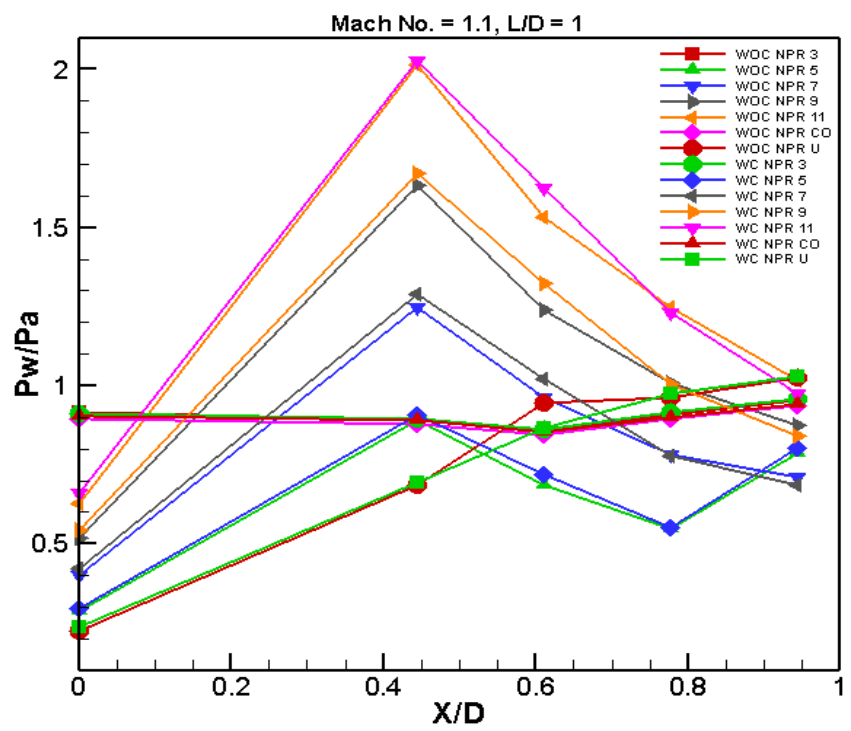

Fig. 4(h). Wall Pressure Vs. X/D

\section{CONCLUSION}

From the above discussions of the results, we may draw the following conclusions which are as follows,

- The control of the base in the re-circulation zone of the base corner and the nature of the flow in the duct by micro jets has been shown.

- The wall pressure takes the lowest value for area ratio 3.24 and $\mathrm{L} / \mathrm{D}$ from 10 to 1 at Mach numbers 1.1 .

- The micro jets seems to be useful at this Mach $\mathrm{M}=$ 1.1 and area ratio 3.24

- The use of micro jets results in a decrement of suction at the base and decrease of associated drag at these combinations of parameters, resulting in an 83 percent increment in the magnitude of base pressure.

- The control by way of micro jets does not negatively affect the static wall pressure of the duct.

\section{REFERENCES}

1. S. A. Khan and E. Rathakrishnan, "Active Control of Suddenly Expanded Flows from Overexpanded Nozzles," International Journal of Turbo and Jet Engines, vol. 19, pp. 119-126, 2002.

2. S. A. Khan and E. Rathakrishnan, "Control of Suddenly Expanded Flow with Micro-Jets," International Journal of Turbo and Jet Engines, vol. 20, pp. 63-82, 2003.

3. S. A. Khan and E. Rathakrishnan, "Control of Suddenly Expanded Flows from Correctly Expanded Nozzles," International Journal of Turbo and Jet Engines, vol. 21, pp. 255-278, 2004.

4. S. Rehman and S. A. Khan, "Control of base pressure with micro-jets: part I," Aircraft Engineering and Aerospace Technology, vol. 80, no. 2, pp. 158-164, 2008.

5. O. Kostic, Z. Stefanovic, and I. Kostic, "CFD modeling of supersonic airflow generated by a $2 \mathrm{D}$ nozzle with and without an obstacle at the exit section," FME Transaction, vol. 43, no. 2, pp. 107-113, 2015

6. F. A. G. M, M. Asadullah, and S. A. Khan, "Experimental Study of Suddenly Expanded Flow From Correctly Expanded Nozzles," ARPN Journal of Engineering and Applied Sciences, vol. 11, no. 16, pp. 10041-10047, 2016.

7. R. F. A. E. The crew, Edinburgh D. Ward Cutler, Statistical Methods for Research Workers. London, 1934.

8. J. D. Quadros, S. A. Khan, and A. A. J, "Investigation of the effect of process parameters on suddenly Expanded flows through an axi-symmetric nozzle for different Mach Numbers using Design of Experiments," in IOP conf. Series: Materials Science and Engineering, 2017, p. 8.

9. J. D. Quadros, S. A. Khan, and A. A. J., "Modelling of Suddenly Expanded Flow Process in Supersonic Mach Regime using Design of Experiments and Response Surface Methodology," Journal of Computational Applied Mechanics, vol. 49, no. 1, pp. 149-160, 2018.

10. J. Quadros and S. A. Khan, "Study of Effect of Flow Parameters on Base Pressure in a Suddenly Expanded Duct at Supersonic Mach Number Regimes using CFD and Design of Experiments," Journal of Applied Fluid Mechanics, vol. 11, no. February 2019, pp. 483-496, 2018.

11. J. D. Quadros, S. A. Khan, and A. J. Antony, "Predictive modeling of suddenly expanded flow process in the Supersonic Mach number regime using response surface methodology," International Journal of Recent Research Aspects ISSN: vol. 4, no. December, pp. 53-58, 2017.

12. J. D. Quadros, S. A. Khan, and A. J. Antony, "Study of base pressure behavior in a suddenly expanded duct at supersonic Mach number regimes using statistical analysis," Journal of Applied Mathematics and Computational Mechanics, vol. 17, no. 4, pp. 59-72, 2018.

13. J. D. Quadros, O. Campus, S. A. Khan, and A. J. Antony, "Base Pressure Behaviour in a Suddenly Expanded Duct at Supersonic Mach Number Regimes using Taguchi Design of Experiments," vol. 22, no. 4, pp. 1077-1097, 2018.

14. J. D. Quadros, S. A. Khan, and A. J. Antony, "Study of Effect of Flow Parameters on Base Pressure in a Suddenly Expanded Duct at Supersonic Mach Number Regimes using CFD and Design of Experiments," Journal of Applied Fluid Mechanics, vol. 11, no. 2, pp. 483-496, 2018.

15. S. A. Khan, A. Aabid, and M. A. A. Baig, "CFD Analysis of CD Nozzle and Effect of Nozzle Pressure Ratio on Pressure and Velocity For Suddenly Expanded Flows," International Journal of Mechanical and Production Engineering Research and Development, vol. 8, no. June, pp. 1147-1158, 2018.

16. ANSYS Inc, "ANSYS FLUENT 18.0: Theory Guidance," Canonsburg PA, 2017. 
17. A. G. M. Fharukh, A. A. Alrobaian, A. Aabid, and S. A. Khan, "Numerical Analysis of Convergent-Divergent Nozzle Using Finite Element Method," International Journal of Mechanical and Production Engineering Research and Development, vol. 8, no. 6, pp. 373-382, 2018.

18. A. Khan, A. Aabid, and S. A. Khan, "CFD analysis of convergent-divergent nozzle flow and base pressure control using micro-JETS," International Journal of Engineering and Technology, vol. 7, no. 3.29, pp. 232-235, 2018.

19. A. Aabid, A. Khan, N. M. Mazlan, M. A. Ismail, M. N. Akhtar, and S. A. Khan, "Numerical Simulation of Suddenly Expanded Flow at Mach 2.2," International Journal of Engineering and Advanced Technology, vol. 8, no. 3, pp. 457-462, 2019.

20. S. A. Khan, A. Aabid, and C. A. Saleel, "CFD Simulation with Analytical and Theoretical Validation of Different Flow Parameters for the Wedge at Supersonic Mach Number," International Journal of Mechanical and Mechatronics Engineering, no. 01, 2019

21. S. A. Khan, A. Aabid, and C. A. Saleel, "Influence of Micro Jets on the Flow Development in the Enlarged Duct at Supersonic Mach number," International Journal of Mechanical and Mechatronics Engineering, vol. 19, no. 01, pp. 70-82, 2019.

22. Z. I. Chaudhary, V. B. Shinde, and S. A. Khan, "Investigation of base flow for an axisymmetric suddenly expanded nozzle with micro JET," International Journal of Engineering \& Technology, vol. 7, pp. 236-242, 2018. 